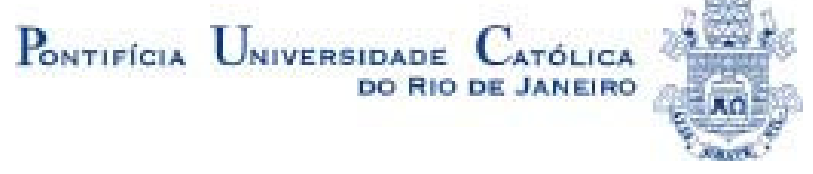

Cristina Pimenta de Mello Spineti Luz

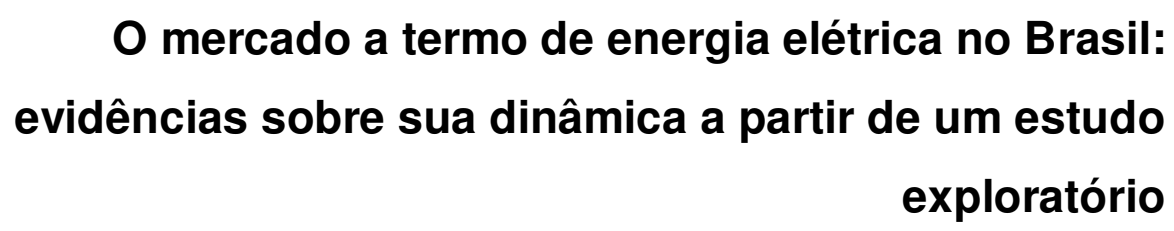

Dissertação de Mestrado

Dissertação apresentada como requisito parcial para obtenção do título de Mestre pelo Programa de PósGraduação em Administração de Empresas da PUCRio.

Orientador: Leonardo Lima Gomes

Rio de Janeiro

Julho de 2011 


\title{
O mercado a termo de energia elétrica no Brasil: evidências sobre sua dinâmica a partir de um estudo exploratório
}

Dissertação apresentada como requisito parcial para obtenção do título de Mestre pelo Programa de PósGraduação em Administração da PUC-Rio. Aprovada pela Comissão Examinadora abaixo assinada.

\author{
Leonardo Lima Gomes \\ Orientador \\ Departamento de Administração - PUC-Rio
}

Luiz Eduardo Teixeira Brandão Departamento de Administração - PUC-Rio

Carlos de Lamare Bastian Pinto

UniGranRio

Mônica Herz

Coordenadora Setorial do Centro de Ciências Sociais - PUC-Rio

Rio de Janeiro, 05 de julho de 2011 
Todos os direitos reservados. É proibida a reprodução total ou parcial do trabalho sem autorização da universidade, da autora e do orientador.

\section{Cristina Pimenta de Mello Spineti Luz}

Graduou-se em Matemática Aplicada pela Universidade Federal do Rio de Janeiro (UFRJ) em 2008, tendo sido bolsista de iniciação científica do CNPq em 2006-2007 e estagiária do Núcleo de Pesquisas em Internacionalização de Empresas (NuPIn/COPPEAD) em 2008. Trabalhou como escriturária no Banco do Brasil entre 2008 e 2010, exercendo diversas atividades negociais e administrativas. É analista da empresa Diferencial Comercializadora de Energia desde janeiro de 2011, executando atividades de acompanhamento do mercado de energia elétrica, previsão de preços, controle interno e contribuições a projetos de P\&D.

Ficha Catalográfica

Luz, Cristina Pimenta de Mello Spineti

O mercado a termo de energia elétrica no Brasil : evidências sobre sua dinâmica a partir de um estudo exploratório / Cristina Pimenta de Mello Spineti Luz ; orientador: Leonardo Lima Gomes. 2011.

79 f. : il. (color.) ; $30 \mathrm{~cm}$

Dissertação (mestrado)-Pontifícia Universidade Católica do Rio de Janeiro, Departamento de Administração, 2011.

Inclui bibliografia

1. Administração - Teses. 2. Comercialização de energia elétrica. 3. Mercado a termo. 4. Prêmio de risco. 5. Contango x normal backwardation. 6 . Curva a termo de mercado. I. Gomes, Leonardo Lima. II. Pontifícia Universidade Católica do Rio de Janeiro. Departamento de Administração. III. Título.

CDD: 658 
À minha família, que me deu todo o apoio e auxílio para concretização deste trabalho. 


\section{Agradecimentos}

A Deus, princípio e fim de tudo que existe.

Ao meu filho, que, em meu ventre, presenciou tantas aulas noturnas e cujos sorrisos dissipavam meu cansaço.

Ao meu esposo e minha mãe, cuja prontidão e disponibilidade foram indispensáveis para a realização deste trabalho.

Ao meu pai, que sempre contribuiu para o meu desenvolvimento acadêmico.

Ao meu irmão, primos, demais familiares e amigos, que direta ou indiretamente, através do estímulo e exemplo, colaboraram com a conclusão deste estudo.

Ao meu orientador, que me apresentou o Setor Elétrico Brasileiro e incentivou a desvendar suas particularidades.

À Diferencial Energia, pelo auxílio financeiro e pela maior vivência do mercado brasileiro de energia.

À Elektro, cujo projeto de $\mathrm{P} \& \mathrm{D}$ contribuiu para definição do tema desta dissertação.

Aos professores do IAG/PUC-Rio, que comigo partilharam parte de seu saber, alimentando minha busca por conhecimento. 


\section{Resumo}

LUZ, Cristina Pimenta de Mello Spineti; GOMES, Leonardo Lima (Orientador). O mercado a termo de energia elétrica no Brasil: evidências sobre sua dinâmica a partir de um estudo exploratório. Rio de Janeiro, 2011. 79 p. Dissertação de Mestrado - Departamento de Administração, Pontifícia Universidade Católica do Rio de Janeiro.

Na década de 1990, diversos países, inclusive o Brasil, entre 1996 e 2003, iniciaram a reestruturação de seus setores elétricos e criaram mercados livres para negociação de energia. O crescimento desses mercados tem demandado a adaptação de instrumentos financeiros de gestão de riscos e retornos as suas especificidades. No Brasil, o mercado tem, ainda, uma estrutura de balcão desorganizado e descentralizado, o que dificulta seu aprendizado. Os contratos a termo de energia elétrica, negociados bilateralmente, no país, são o principal instrumento para a mitigação de riscos e a avaliação de investimentos. Nesse contexto, o objetivo deste estudo é compreender melhor a dinâmica dos preços a termo de energia elétrica praticados no Brasil. Assim, é proposto um método para construção de curvas a termo com base apenas em informações de mercado e feita uma primeira aplicação dessa metodologia. Alguns indícios ficaram, então, evidentes sobre o comportamento do mercado brasileiro a termo de energia elétrica: configuração de contango em alguns períodos, presença de elevados prêmios de risco e aderência apenas relativa dos preços a termo às expectativas de futuros preços à vista. Estudos realizados a partir de mercados estruturados de energia elétrica suportam essas evidências.

\section{Palavras-chave}

Comercialização de energia elétrica; mercado a termo; prêmio de risco; contango x normal backwardation; curva a termo de mercado. 


\section{Abstract}

LUZ, Cristina Pimenta de Mello Spineti; GOMES, Leonardo Lima (Advisor). The foward market of electricity in Brazil: evidence about his behavior from an exploratory study. Rio de Janeiro, 2011. 79 p. MSc. Dissertation - Departamento de Administração, Pontifícia Universidade Católica do Rio de Janeiro.

In the 1990s, several countries, including Brazil, between 1996 and 2003, began to restructure their electricity sectors and established free markets for energy trading. The growth of these markets has required the adaptation of financial instruments for risk management and return to their specifications. In Brazil, the market has still a disorganized and decentralized OTC (over the counter market) structure, which hinders their learning. The forward contracts for electricity, negotiated bilaterally, in the country, are the primary instrument to mitigate risks and evaluate investments. In this context, the objective of this study is to better understand the dynamics of the forward price of electricity negotiated in Brazil. Thus, we propose a method to construct the forward curve based only on market information and made a first application of this methodology. Some clues were then evident on the behavior of the Brazilian forward market of electricity: contango set in certain periods, presence of high risk premiums and only partial adherence of forward prices on the expectations of future spot prices. Studies based on structured electricity markets support these evidences.

\section{Keywords}

Electricity trading; foward market; risk premium; contango $\mathrm{x}$ normal backwardation; the market foward curve. 


\section{Sumário}

1 Introdução 12

$\begin{array}{ll}\text { 1.1. Objetivos } & 14\end{array}$

1.2. Delimitação do estudo 14

1.3. Relevância do estudo 15

$\begin{array}{ll}\text { 1.4. Estrutura da dissertação } & 16\end{array}$

2 Revisão de literatura $\quad 17$

2.1. Mercados a termo e futuros 17

2.1.1. Formação de preços a termo e futuros 18

2.1.2. Comportamento dos mercados a termo e futuros 20

2.2. Curva a termo de mercado 22

2.2.1. Valor de um contrato a termo 23

2.2.1.1. Taxa livre de risco 23

2.2.2. Curva a termo de taxa de juros 24

2.3. Energia elétrica como commodity 25

2.3.1. Contrato a termo de energia elétrica 26

2.3.2. Curva a termo de energia elétrica 26

2.4. Mercados a termo e futuros de energia elétrica 28

2.4.1. Comportamento dos mercados 29

3 O Setor Elétrico Brasileiro (SEB) 33

3.1. Breve histórico 36

3.2. Comercialização de energia no Sistema Interligado Nacional (SIN) 44

3.2.1. Contratos bilaterais de compra e venda de energia elétrica negociados no ACL

3.3. O Preço de Liquidação das Diferenças (PLD) e o preço à vista da $\begin{array}{ll}\text { energia elétrica } & 47\end{array}$

3.3.1. Enfoque econômico da operação de um sistema hidrotérmico 48

3.3.2. Cálculo do Preço de Liquidação das Diferenças (PLD) 50

4 Metodologia 53 
4.1. Curva a termo de energia elétrica para o mercado brasileiro com base apenas em informações de mercado 53

4.2. Preço à vista atual e esperado para o futuro da energia elétrica 58

4.2.1. Filtro de PLD 60

4.3. Coleta de dados 62

4.4. Análise dos dados 62

5 Resultados $\quad 64$

5.1. Eficiência do filtro de PLD 64

5.2. Evidências sobre o comportamento do mercado a termo de energia elétrica brasileiro 68

6 Conclusão e recomendações $\quad 73$

6.1. Conclusão 73

6.2. Sugestões para trabalhos futuros $\quad 74$

$\begin{array}{ll}7 \text { Referências bibliográficas } & 75\end{array}$ 


\section{Lista de tabelas}

Tabela 1 - Volatilidade histórica anual do PLD

Tabela 2 - Capacidade de geração hidroelétrica instalada nos principais rios brasileiros por região

Tabela 3 - Expansão anual da rede de transmissão brasileira em km 35

Tabela 4 - Histórico da formação do preço no Mercado de Curto Prazo 52

Tabela 5 - Resultados do 10ำ Leilão de Ajuste (2011) 49

Tabela 6 - Quantidade de séries filtradas por mês em 201065

Tabela 7 - Valores médios de PLD (R\$/MWh) observados em 2010/2011

Tabela 8 - Comparação de estimadores para os submercados

Sudeste/Centro-Oeste e Sul

66

Tabela 9 - Comparação de estimadores para os submercados Nordeste e Norte 


\section{Lista de figuras}

Figura 1 - Capacidade de geração de energia elétrica instalada no Brasil em 31/12/2010 por tipo de fonte geradora 34

Figura 2 - Integração eletroenergética brasileira em $2010 \quad 36$

Figura 3 - Diagrama das instituições do Setor Elétrico Brasileiro (SEB) 42

Figura 4 - Energia Comercializada no Mercado de Curto Prazo 45

Figura 5 - Processo de decisão em um sistema hidrotérmico 49

Figura 6 - Custos da operação: imediato e futuro 49

Figura 7 - Decisão ótima da operação sob ponto de vista econômico 50

Figura 8 - Evolução do ganho de eficiência por submercado do filtro de

PLD (baseado no erro quadrático médio dos estimadores) em relação ao mês previsto

Figura 9 - Evolução do ganho de correlação por submercado do filtro de PLD em relação ao mês previsto

Figura 10 - Evolução do prêmio de risco em relação ao tempo até a maturidade quando a expectativa de preço à vista futuro é inferior a $\mathrm{R} \$$ 100/MWh

Figura 11 - Evolução do prêmio de risco em relação ao tempo até a maturidade quando a expectativa de preço à vista futuro é superior a $R \$$ 100/MWh

Figura 12 - Evolução curva da curva a termo: fevereiro/março $2011 \quad 71$

Figura 13 - Evolução da curva a termo: março/abril 2011 